\title{
Predição do Consumo Voluntário do Capim-Tanzânia (Panicum maximum, J. cv. tanzânia), sob Pastejo, por Vacas em Lactação, a partir das Características de Degradação ${ }^{1}$
}

\author{
João Paulo Guimarães Soares ${ }^{2,7}$, Ana Karina Dias Salman 3, 7 , Telma Teresinha Berchielli4, 6 , \\ Luiz Januário Magalhães Aroeira ${ }^{5,6}$, Rui da Silva Verneque ${ }^{5,6}$
}

RESUMO - O consumo de matéria seca (CMS) do capim tanzânia de 24 vacas lactantes mestiças (HPB x Gir) e Gir, sob pastejo, foi estimado no mês de janeiro de 1998, a partir da relação entre a digestibilidade da MS da forragem e a produção fecal obtida com auxílio do cromo mordente por meio de um modelo não-linear. Os resultados do consumo estimado foram comparados aos consumos preditos por diferentes equações baseadas nos dados de degradabilidade do capim, no rúmen. A pastagem foi manejada com taxa de lotação de dois animais/ha, em sistema de pastejo rotativo com três dias de ocupação do piquete e 39 dias de descanso. Foram utilizadas para predizer o CMS diferentes equações: CMS $=-1,19+0,035(\mathrm{a}+\mathrm{b})+28,5 \mathrm{c}(1), \mathrm{CMS}=-0,822+0,0748(\mathrm{a}+\mathrm{b})+40,7 \mathrm{c}(2), \mathrm{CMS}=-8,286+0,266 \mathrm{a}$ $+0,102 b+17,696 \mathrm{c}(3)$ e CMS $=[\% \text { FDN na MS }]^{*}$ [consumo de FDN $\left.] /\left[(1-a-b) / K_{P}+b /\left(c+k_{p}\right)\right] / 24\right](4)$. As equações, em geral, subestimaram o consumo obtido no modelo não-linear ( $9,6 \mathrm{~kg} / \mathrm{vaca} / \mathrm{dia})$. Os consumos médios de capim de 6,2 e 6,0 kg MS/vaca/dia obtidas, respectivamente, nas equações de (2) e (4) foram semelhantes entre si e inferiores ao das equações de (1) (12,7 kg/vaca/dia) e (3) $(8,1 \mathrm{~kg} / \mathrm{vaca} / \mathrm{dia})$. A predição do consumo de forrageiras tropicais, sob pastejo, utilizando-se as equações baseadas nas variáveis da degradação in situ, constitui um importante potencial para estas avaliações. Entretanto, mais estudos dessa natureza devem ser realizados para validar o uso destas equações na prática.

Palavras-chave: cromo mordente, degradabilidade, estimativa de consumo, equações de predição, forrageiras tropicais, pastagem

\section{Prediction of Tanzania Grass (Panicum Maximum, J.) Voluntary Intake, under Grazing by Lactating Cows, from Degradation Characteristics}

\begin{abstract}
Dry matter intake (DMI) of Tanzania grass under grazing conditions was estimated using 24 Holstein-Zebu and Gir cows from the in vitro dry matter digestibility of extrusa samples (esophageal fistulated cows) and fecal output. The fecal output was estimated using chromium mordant and a non-linear model. The pasture was managed in a rotational system with three days paddock occupation and 39 days of resting period. The stocking rate was $2.0 \mathrm{cows} /$ ha during the rainy season. Four different equations based on in situ degradation characteristics were used to predict DMI: DMI $=-1.19+0.035(\mathrm{a}+\mathrm{b})+28.5 \mathrm{c}(1), \mathrm{DMI}=-0.822+0.0748(\mathrm{a}+\mathrm{b})+$ $40.7 \mathrm{c}(2), \mathrm{DMI}=-8.286+0.266 \mathrm{a}+0.102 \mathrm{~b}+17.696 \mathrm{c}(3)$ and DMI $=[\% \text { FDN MS }]^{*}[$ FDN intake $\left.] /\left[(1-\mathrm{a}-\mathrm{b}) / \mathrm{K}_{\mathrm{P}}+\mathrm{b} /\left(\mathrm{c}+\mathrm{k}_{\mathrm{p}}\right)\right] / 24\right](4)$. The DMI predicted from the equations, in general, underestimated the results obtained with the non-linear model (9.6 kg DM/cow/day). The DMI data using the equations (2) and (4) $(6.2$ and $6.0 \mathrm{~kg}$ of DM/cow/day) were similar and different from the results obtained using equations (1) (12.7 kg DM/cow/day) and (3) (8.1 kg DM/cow/day). All the DMI were underestimated in relation to results from the non-linear model, except those from equation (1). The prediction of tropical forages intake, under grazing condition using equations based in degradation characteristics constitute an important tool for these evaluations. Eventhough, more studies need to be done to validate these equations in practice.
\end{abstract}

Key Words: degradability, intake, mordanted chromium, pastures, prediction equations, tropical forages

\section{Introdução}

O consumo de nutrientes é o principal fator a influenciar o processo de conversão do alimento em tecidos e produtos de origem animal. No entanto, existe uma grande dificuldade de se avaliar este consumo devido a fatores relacionados ao animal, ao ambiente e ao alimento, os quais são difíceis de serem separados (MERTENS, 1994). Existem várias metodologias, diretas e indiretas, para se medir consumo no pasto, porém todas apresentam limitações e comprometimentos que podem induzir a erros (OWENS e HANSON, 1992).

Um dos métodos utilizados para se estimar a

\footnotetext{
${ }^{1}$ Trabalho financiado pela FAPESP.

${ }^{2}$ Pesquisador da Embrapa Rondônia, Doutorando - FCAV/UNESP - Jaboticabal-SP. E.mail: jpsoares@fcav.unesp.br

3 Doutoranda - FMVZ/UNESP - Botucatu, SP.E.mail: akdias@hotmail.com.br

${ }^{4}$ Professora UNESP/Jaboticabal, SP. E.mail: ttberchi@fcav.unesp.br

${ }^{5}$ Pesquisador da Embrapa Gado de Leite - Juiz de Fora, MG. E.mail: laroeira@cnpgl.embrapa.br

6 Pesquisador do CNPq.

7 Bolsista da FAPESP.
} 
ingestão de matéria seca (IMS) por animais em pasto, é a relação entre a produção fecal (PF) dos animais e a digestibilidade in vitro da matéria seca (DIVMS) da forragem, segundo a equação: IMS = $\mathrm{PF} /(1-\mathrm{DIVMS})$, onde a PF é determinada com o auxílio de marcadores externos, como o cromo mordente (AROEIRA,1997). Esse método vem sendo questionado pelas dificuldades relacionadas com a utilização do cromo mordente, pelas características do alimento (taxa de passagem lenta) (FURLAN, 1998) ou pela liberação lenta do indicador (PIAGGIO et al., 1991). Além disso, há uma baixa recuperação desse indicador nas fezes, causada pela perda de cromo durante a marcação da FDN (COLUCCI, 1984), o que pode subestimar as produções fecais, levando, conseqüentemente, a erros nas estimativas de consumo.

Vários trabalhos vêm sendo realizados sobre predição do potencial de ingestão e da digestibilidade dos alimentos a partir de seus componentes químicos. Este método, no entanto, é criticado pelo fato de a ingestão e a digestibilidade dos alimentos, em ruminantes, serem influenciadas não somente pela composição química dos alimentos, mas também pelo manejo alimentar (MERTENS, 1987).

$\mathrm{O}$ uso da técnica in situ para avaliar alimentos tem se tornado um método alternativo devido a sua simplicidade e natureza direta, além de tornar possível a determinação das taxas de degradação (HOVELL, 1986). O AFRC (1993) vem adotando a técnica in situ como o método padrão para caracterizar a degradabilidade ruminal do nitrogênio e por apresentar resultados semelhantes àqueles obtidos pela técnica in vivo.

Segundo VON KEYSERLINGK e MATHISON (1989), a técnica in situ poderia ser mais eficiente como método para estimar a digestibilidade e a ingestão voluntária de forragens se a taxa de passagem e de degradação fossem medidas e utilizadas para predizer estes fatores, pois apresenta uma alta correlação com a ingestão voluntária $(\mathrm{R}=0,82)$ quando comparado à digestibilidade in vivo (CHENOST et al., 1970).

HOVEL et al. (1986), ØRSKOV et al. (1988) e SHEM et al. (1995) usaram as variáveis $a, b$ e $c$ da fórmula: $Y(t)=a+b\left(1-e^{-c t}\right)$, para descrever a degradabilidade da MS ou da PB, incubadas em sacos de náilon no rúmen (ØRSKOV e McDONALD, 1979) e predizer consumo de um alimento. Este método, entretanto, também apresentou limitações, já que alguns alimentos não apresentam padrões de degradação que seguem o modelo proposto. Para superar este problema, MADSEN et al. (1994) desenvolveram um método, no qual a taxa de degradação do alimento no rúmen é combinada com sua taxa de passagem, com o objetivo de se estimar o enchimento físico do órgão. O consumo potencial do alimento é descrito pelo seu enchimento do rúmen e a unidade usada é dia. A capacidade de um animal de ingerir o alimento é fornecida em kg. O consumo é, então, predito em kg/dia, dividindo-se a capacidade de ingestão do animal $(\mathrm{kg})$, pelo enchimento do rúmen (dia). Como o enchimento do rúmen é causado, principalmente pela fração fibrosa do alimento, as variáveis de degradação e a taxa de passagem baseiam-se no FDN da forrageira avaliada (MADSEN et al., 1997).

Este estudo teve como objetivo comparar quatro equações de predição de consumo voluntário de matéria seca a partir dos parâmetros de degradação in situ com o método que considera a relação entre a digestibilidade in vitro da matéria seca da forragem e a produção fecal obtida por meio de um modelo nãolinear, utilizando vacas em lactação mestiças e Gir em pastagem de capim-tanzânia.

\section{Material e Métodos}

O pasto de capim-tanzânia (Panicum maximum, J. cv. Tanzânia) no período anterior ao início do experimento foi adubado com $150 \mathrm{~kg}$ de nitrogênio/ha divididos em três aplicações, dos quais na primeira aplicaram-se $250 \mathrm{~kg}$ de adubo N-P-K (20-0-20) e $300 \mathrm{~kg}$ de superfosfato simples, o que correspondeu a $50 \mathrm{~kg}$ de nitrogênio/ha. Os $100 \mathrm{~kg}$ de nitrogênio restantes foram aplicados, na forma de sulfato de amônio (250 kg por aplicação), em duas aplicações com intervalo de três meses.

O experimento foi conduzido no mês de janeiro de 1998 utilizando-se uma área de 15,8 ha, dividida em 14 piquetes de 1,1 ha, pastejada por 29 vacas em lactação, 20 mestiças (Gir x HPB) e nove Gir, permitindo uma taxa de lotação de duas vacas/ha. O manejo da pastagem era rotativo, com período de ocupação de três dias e com 39 dias de descanso.

Para as determinações dos consumos foram utilizadas 24 vacas com seis meses de lactação em média, subdivididas em três grupos. Oito com vacas puras da raça Gir, oito vacas mestiças (Gir x HPB), sendo ambos os grupos em regime exclusivo de pasto,

Rev. bras. zootec., 30(6S):2176-2182, 2001 
e também com oito vacas mestiças (Gir x HPB) que recebiam, além da forragem no pasto, suplementação de concentrado, na quantidade fixa de três $\mathrm{kg} / \mathrm{animal} /$ dia. O concentrado oferecido era composto por $72,2 \%$ de milho, $25,3 \%$ de farelo de soja e 2,5\% de minerais.

Os animais foram agrupados por produção de leite na lactação anterior, e durante todo período permaneceram na pastagem de capim tanzânia.

Para a coleta de extrusas de cada piquete, utilizaram-se quatro vacas secas, fistuladas no esôfago, sendo duas mestiças (Gir x HPB) e duas Gir, que foram colocadas na pastagem antes da entrada dos animais experimentais nos piquetes.

Os animais foram submetidos a jejum prévio de 12 horas e as coletas foram feitas durante 30 minutos. Coletaram-se as extrusas referentes a cada vaca, as quais foram misturadas e secas em estufa de circulação forçada de ar a $55^{\circ} \mathrm{C}$.

As amostras secas foram divididas em três porções: a primeira foi usada para determinação da digestibilidade in vitro da matéria seca (TYLLEY e TERRY, 1963), a segunda para o tratamento da fibra em detergente neutro com dicromato de sódio $\left(\mathrm{Na}_{2} \mathrm{Cr}_{2} \mathrm{O}_{7} \cdot 2 \mathrm{H}_{2} \mathrm{O}\right)$, COLUCCI (1984) e a terceira para a determinação da degradabilidade in situ da matéria seca (MEHREZ e ØRSKOV, 1977).

A produção fecal foi estimada, nos 24 animais em pastejo, utilizando-se a FDN da extrusa mordentada com dicromato de sódio. O alimento marcado foi pesado e colocado em balas de papeltoalha, com aproximadamente $3 \mathrm{~g}$. Cerca de $30 \mathrm{~g}$ desse material foi administrado a cada animal, em dose única, por via oral, com o auxílio de uma sonda.

A coleta de fezes foi feita diretamente no reto às $6,9,12,24,32,36,48,56,72,80,96,104$, e 120 horas após a administração das cápsulas. A excreção fecal dos alimentos nos períodos experimentais foi obtida com base na relação: quantidade de indicador administrado/concentração do indicador nas fezes.

As amostras de fezes foram analisadas em laboratório para determinação do teor de cromo nas amostras. A partir dos resultados obtidos de cromo fecal foram confeccionadas as curvas de excreção para estimativas de consumo da dieta. As produções fecais e as taxas de passagem no rúmen foram calculadas utilizando-se as estimativas dos parâmetros do modelo proposto por POND et al. (1989), analisadas estatisticamente pelo SAS (1990).

A produção fecal total (PFT) diária foi obtida com base na seguinte relação:

Rev. bras. zootec., 30(6S):2176-2182, 2001

$$
\mathrm{Y}=\left[\mathrm{K}_{0} \mathrm{~L}_{1}(\mathrm{t}-\mathrm{t}) \cdot \mathrm{e}^{-(\mathrm{L} 1(\mathrm{t}-\mathrm{t}))}\right] / 0,59635
$$

em que: $\mathrm{Y}=$ concentração do marcador; $\mathrm{K}_{0}=$ concentração do marcador, se este é misturado instantaneamente no compartimento; $\mathrm{L}_{1}=$ parâmetro de taxa de passagem dependente do tempo; $t=$ tempo decorrido da administração até o primeiro aparecimento do marcador nas fezes; $\mathrm{t}=$ tempo após a administração do marcador.

O consumo de MS de forragem (CMS) foi calculado pela fórmula:

$$
\text { CMS = Produção fecal / (1 - DIVMS) }
$$

em que: $\mathrm{CMS}$ = consumo de MS diária em $\mathrm{kg}$; $\mathrm{PF}=$ produção fecal em $\mathrm{g} / \mathrm{MS} / \mathrm{vaca} / \mathrm{dia}$; DIVMS = digestibilidade in vitro da extrusa.

O consumo de matéria seca de capim no grupo de animais suplementados com concentrado foi calculado de forma indireta, ou seja, subtraindo-se as produções fecais calculadas a partir da digestibilidade do concentrado da excreção fecal total obtida no modelo.

A degradabilidade in situ da extrusa foi realizada ao término do ensaio de consumo. Para tanto, utilizaram-se três vacas mestiças, não-lactantes, fistuladas no rúmen, as quais foram previamente adaptadas em pastagem de capim-tanzânia. Aproximadamente $5 \mathrm{~g}$ de extrusa seca foram acondicionados em sacos de náilon $(7 \times 14 \mathrm{~cm})$ incubados no rúmen por 3, 6, 12, 24, $48,96,120 \mathrm{~h}$, os quais foram previamente incubados em solução tampão (McDOUGALL, 1939) a $39^{\circ} \mathrm{C}$ por uma hora.

Para o cálculo da degradabilidade in situ da matéria seca (MS), foi utilizada a equação proposta por MEHREZ e ØRSKOV (1977), com recomendações propostas por NOCEK e KOHN (1988), expressa por:

$$
\mathrm{P}=\mathrm{a}+\mathrm{b}\left(1-\mathrm{e}^{-\mathrm{ct}}\right)
$$

em que: $\mathrm{P}=$ quantidade de nutriente degradado no tempo $\mathrm{t} ; \mathrm{a}=$ fração rapidamente solúvel em água, $\mathrm{b}=$ fração insolúvel em água, mas potencialmente degradável; $\mathrm{c}=$ taxa de degradação da fração $\mathrm{b}$.

A degradabilidade efetiva (DE) foi calculada considerando-se as taxas de passagem estimadas para cada grupo de vacas do experimento de consumo pelo modelo de POND et al. (1989), segundo a equação proposta por $\varnothing \mathrm{RSKOV}$ e McDONALD (1979):

$$
\mathrm{DE}=\mathrm{a}+(\mathrm{b} \mathrm{c}) / \mathrm{c}+\mathrm{k}_{\mathrm{P}}
$$

em que: $\mathrm{a}=$ fração rapidamente solúvel em água; $\mathrm{b}$ = fração insolúvel em água, mas potencialmente degradável; $c$ = taxa de degradação da fração b; $\mathrm{k}_{\mathrm{P}}=$ taxa de passagem.

A partir dos parâmetros de degradação foram estimados os consumos pelas equações propostas por: 
VON KEYSERLINGK e MATHISON (1989), onde IMS $=-1,19+0,035(\mathrm{a}+\mathrm{b})+28,5 \mathrm{c}\left(\mathrm{R}^{2}=86 \%\right)$; $\varnothing \mathrm{RSKOV}$ et al. (1988), onde IMS $=-0,822+0,0748$ (a + b) $+40,7$ c $\left(\mathrm{R}^{2}=89 \%\right)$; SHEM et al. (1995), onde IMS $=-8,286+0,266 \mathrm{a}+0,102 \mathrm{~b}+17,696 \mathrm{c}\left(\mathrm{R}^{2}=90 \%\right) \mathrm{e}$ MADSEN et al. (1997), onde IMS $=[\% \mathrm{FDN} \text { na MS }]^{*}$ [Ingestão de FDN] / [(1-a - b) / $\left.\mathrm{K}_{\mathrm{P}}+\mathrm{b} /\left(\mathrm{c}+\mathrm{k}_{\mathrm{p}}\right)\right] / 24$.

As amostras das extrusas e do concentrado utilizados pré-secos e moídos foram analisadas para fibra em detergente neutro (FDN), fibra em detergente ácido (FDA) pelo método proposto por VAN SOEST (1965). Para as análises da digestibilidade in vitro da matéria seca (DIVMS), seguiram-se as recomendações de TILLEY e TERRY (1963). As determinações de cromo nas fezes foram feitas a partir de digestão nitroperclórica e a leitura a partir do método colorimétrico.

O delineamento experimental adotado para a comparação dos modelos foi o inteiramente casualizado. A análise de variância e as médias foram comparadas pelo teste SNK a 5\%, pelo programa ANOVA (SAS, 1990) e segundo o modelo:

$$
\mathrm{Y}_{\mathrm{ij}}=\mu+\mathrm{t}_{\mathrm{i}}+\mathrm{m}_{\mathrm{j}}+\mathrm{tm}_{\mathrm{ij}}+\mathrm{e}_{\mathrm{ij}}
$$

em que: $\mathrm{Y}_{\mathrm{ij}}=$ valor para característica consumo em kg/dia; \%PV e g/PV ${ }^{0.75}$ de MS, dos capim-tanzânia da

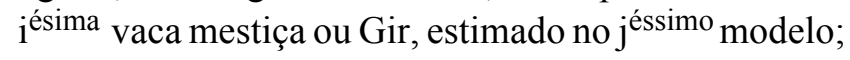
$\mu=$ média geral constante comum a cada observação; $\mathrm{t}_{\mathrm{i}}=$ efeito do tratamento $\mathrm{i}(\mathrm{i}=1 \mathrm{a} 3) ; \mathrm{m}_{\mathrm{j}}=$ efeito do modelo $\mathrm{j}(\mathrm{j}=1$ a 5$) ; \mathrm{tm}_{\mathrm{ij}}=$ efeito da interação tratamento $\mathrm{x}$ modelo; $\mathrm{e}_{\mathrm{ij}}=$ erro residual aleatório.

\section{Resultados e Discussão}

A composição bromatológica e digestibilidade in vitro da matéria seca da extrusa, coletada por meio de animais com fístulas no esôfago e do concentrado utilizado, podem ser observadas na Tabela 1 .
Não foram observadas diferenças significativas $(\mathrm{P}<0,05)$ entre os tratamentos estudados, utilizandose os grupos de vacas lactantes mestiças (HPB x Gir) e Gir para os valores de consumo obtidos com o capim tanzânia, e que foram somente estimados pelo método convencional, ou seja, com o auxílio do modelo não-linear descrito por POND et al. (1989). Podendo estes resultados serem observados na Tabela 2.

Diferente desses resultados, FURLAN (1998) verificou maior ingestão de matéria seca total em vacas mestiças quando comparadas com vacas Gir (1,58 e 1,38\% do peso vivo) em pastagem de capimcoastcross. EUCLIDES et al. (1999), trabalhando com novilhos, estimaram o consumo de matéria seca de capim tanzânia e encontrou média de $2,46 \%$ do peso vivo, resultado similar ao deste experimento que está amplamente discutido em SALMAN (1999).

Para o cálculo do consumo por meio das equações de predição, objeto do presente estudo, foram utilizadas as variáveis obtidas a partir do ensaio de degradação in situ da MS da extrusa do capimtanzânia que apresentaram os seguintes resultados: fração solúvel (a) de 6,4\%; fração insolúvel potencialmente degradável (b) de 75,05\% e taxa de degradação da fração b (c) de 3,82\%/hora.

Os dados referentes ao consumo de matéria seca do capim-tanzânia para os animais experimentais são os valores médios preditos pelas diferentes equações, e o estimado pelo modelo não-linear, o que se deve à não detecção de diferença significativa entre os grupos experimentais compostos pelas vacas mestiças (HPB x Gir) e Gir, como já descrito (Tabela 3).

As equações subestimaram o consumo obtido no modelo POND et al. (1989) (9,6 kg/vaca/dia), com exceção de VON KEYSERLINGK e MATHISON (1989), que superestimaram, no entanto em termos numéricos o valor observado na equação descrita por

Tabela 1 - Composição da forragem coletada por meio de animais fistulados no esôfago (extrusa), do concentrado e digestibilidade in vitro da matéria seca.

Table 1 - Composition of grass collected from esophageal fistulated animal (extrusa),concentrate and dry matter in vitro digestibility

\begin{tabular}{lccccc}
\hline$\%$ da matéria seca & MS (\%) & PB & FDN & FDA & DIVMS \\
\% of dry matter & $D M(\%)$ & $C P$ & $N D F$ & $A D F$ & DMIVD \\
Extrusa & 13,8 & 12,1 & 78,8 & 42,6 & 66,5 \\
$\begin{array}{l}\text { Extrusa } \\
\text { Concentrado }\end{array}$ & & & & \\
Concentrate & 88,7 & 19,9 & 27,0 & 5,8 & 97,5
\end{tabular}

$\mathrm{MS}=$ matéria seca, $\mathrm{PB}=$ proteína bruta, FDN = fibra em detergente neutro, FDA= fibra em detergente ácido.

$D M=$ dry matter, $C P=$ crude protein, NDF = neutral detergent fiber, $A D F=$ acid detergent fiber, $D M I V D=$ dry matter in vitro digestibility.

Rev. bras. zootec., 30(6S):2176-2182, 2001 
Tabela 2 - Peso vivo (PV), consumo de matéria seca (CMS) do capim e do concentrado (Conc.) e relação entre a ingestão de matéria seca e o peso vivo, em porcentagem (\%PV) para os três grupos experimentais: mestiças com concentrado (1), mestiças sem concentrado (2) e Gir sem concentrado (3)

Table 2 - Live weight of the cows (LW), dry matter intake (DMI) of grass and concentrate (Conc.) and the relation between dry matter intake and live weight, in percentage, for the three experimental group: crossbred with concentrate (1), crossbred without concentrate(2) and Gir without concentrate(3)

\begin{tabular}{|c|c|c|c|c|c|c|c|}
\hline \multirow[t]{2}{*}{$\begin{array}{l}\text { Grupos experimentais } \\
\text { Experimental groups }\end{array}$} & \multicolumn{4}{|c|}{$\begin{array}{c}\text { CMS (kg/vaca) } \\
\text { DMI (kg/cow) }\end{array}$} & \multicolumn{3}{|c|}{$\begin{array}{l}\text { CMS }(\% \mathrm{PV}) \\
D M I(\% L W)\end{array}$} \\
\hline & $\begin{array}{l}\text { PV } \\
L W\end{array}$ & $\begin{array}{l}\text { Capim } \\
\text { Grass }\end{array}$ & $\begin{array}{l}\text { Conc. } \\
\text { Conc. }\end{array}$ & $\begin{array}{l}\text { Total } \\
\text { Total }\end{array}$ & $\begin{array}{l}\text { Capim } \\
\text { Grass }\end{array}$ & $\begin{array}{l}\text { Conc. } \\
\text { Conc. }\end{array}$ & $\begin{array}{l}\text { Total } \\
\text { Total }\end{array}$ \\
\hline 1 & $504^{\mathrm{a}}$ & $8,26^{a} \pm 5,66$ & 2,59 & $10,85^{\mathrm{a}}$ & 1,63 & 0,52 & $2,15^{\mathrm{a}}$ \\
\hline 2 & $495^{\mathrm{a}}$ & $11,01^{a} \pm 5,37$ & - & $11,01^{\mathrm{a}}$ & 2,37 & - & $2,37^{\mathrm{a}}$ \\
\hline 3 & $418^{b}$ & $9,55^{\mathrm{a}} \pm 2,31$ & - & $9,55^{\mathrm{a}}$ & 2,34 & - & $2,34^{\mathrm{a}}$ \\
\hline Média & 472 & 9,6 & - & 10,5 & 2,1 & - & 2,3 \\
\hline
\end{tabular}

a,b Médias, na mesma coluna, seguidas de letras diferentes, são diferentes $(\mathrm{P}<0,01)$ pelo teste de SNK.

$a, b$ Means, in the same column, followed by different letters are different $(P<0.01)$ by the SNK test.

SHEM et al. (1995), (8,1 kg/vaca/dia), sendo o que mais se aproximou do resultado estimado no modelo não-linear.

Os consumos médios de capim de 6,2 e $6,0 \mathrm{~kg}$ MS/ vaca/dia, obtidos nas equações de ÆRSKOV et al. (1988) e MADSEN et al. (1997), respectivamente, foram semelhantes entre si $(\mathrm{P}>0,05)$ e inferiores $(\mathrm{P}<0,05)$ ao das equações de VON KEYSERLINGK e MATHISON (1989) (12,7 kg/vaca/dia) e SHEM et al. (1995) $(8,1 \mathrm{~kg} / \mathrm{vaca} / \mathrm{dia})$.

Em estudos das características de degradação in situ de forragens (a. MS, b. MS e c. MS), verifica-se o quanto os parâmetros de degradação influenciam na utilização do alimento pelo animal e sua relação com a ingestão. Segundo MERTENS (1987), a utilização destes parâmetros podem levar a um aumento de precisão na ingestão de matéria seca e de matéria orgânica, por meio da relação (a.MS + b.MS + c.MS).

O resultado obtido por VON KEYSERLINGK e MATHISON (1989) em relação à porcentagem do peso vivo, embora superestimando os valores obtidos no modelo não-linear $(2,75 \%)$, foi o que mais se aproximou dos valores obtidos por EUCLIDES et al. (1993) (2,47\%) e EUCLIDES et al. (1999) (2,46\%), trabalhando também com o capim-tanzânia sob pastejo, porém utilizando o óxido crômico. Estes resultados podem estar relacionados à utilização dos parâmetros $\mathbf{a}, \mathbf{b}$ e c, que, segundo os próprios autores, superestimaram os valores obtidos em estudos para forragens de melhor qualidade.

As estimativas de ingestão de matéria seca foram bem diferentes quando se consideraram as frações (a) e (b), nas equações de predição, no entanto, a inclusão das taxas de degradação (c) e passagem de partículas $\left(\mathrm{K}_{\mathrm{p}}\right)$ deveriam aumentar a precisão nas estimativas de ingestão, principalmente com relação às equações de SHEM et al. (1995) e ØRSKOV et al. (1988).

$\mathrm{O}$ uso dos coeficientes desenvolvidos por $\varnothing \mathrm{RSKOV}$ et al. (1988) na equação $\left((\mathrm{A}+\mathrm{B})+\mathrm{K}_{\mathrm{d}}\right)$ resultou na estimativa das ingestões diárias de $6,2 \mathrm{~kg}$ $\mathrm{MS} /$ dia, indicando que sua equação subestimou o consumo da forragem. Isto já era esperado, uma vez que a mesma equação foi desenvolvida utilizando-se palhas. Entretanto, o valor obtido pela equação proposta por SHEM et al. (1995) $(8,1 \mathrm{~kg} \mathrm{MS} /$ dia) foi o mais próximo ao valor estimado pelo modelo nãolinear descrito por POND et al. (1989), podendo ter apresentado valor mais correto, pois teria sido desenvolvida utilizando forrageiras tropicais.

O coeficiente de variação obtido para os valores estimados do consumo em $\mathrm{kg}$ MS/dia (26,7\%) (Tabela 3) foi inferior aos obtidos HOVELL et al. (1986), em que estes autores observaram que as informações dos sacos de náilon explicam $98 \%$ da variação na ingestão, e que 35,75 e $94 \%$ de variabilidade foram explicadas pelos teores de PB, FDN e FDA do alimento, respectivamente. Dessa forma, o valor de FDN encontrado para a extrusa foi bastante alto $(78,8 \%)$ (Tabela 1$)$ e pode ter limitado o consumo de matéria seca, pois segundo VAN SOEST (1994), valores acima de 55 a $60 \%$ de FDN na matéria seca limitam o consumo de forragem.

As equações de SHEM et al. (1995) e ØRSKOV et al. (1988) foram as que apresentaram coeficiente de determinação mais elevado $\left(\mathrm{R}^{2}=0,90\right.$ e 0,89$)$, 


\section{Referências Bibliográficas}

AGRICULTURAL AND FOOD RESEARCH COUNCIL AFRC. 1993. Energy and protein requirements of ruminants. Wallingford: CAB International. 159p.

AROEIRA, L.J.M. Estimativas de consumo de gramíneas tropicais. In: SIMPÓSIO INTERNACIONAL DE DIGESTIBILIDADE EM RUMINANTES, 1997, Lavras, MG. Anais... Lavras: UFLA-FAEPE, 1997. p.127-163.

CHENOST, M., GRENET, E., DEMARQUILLY, C. et al. The use of the nylon bag technique for the study forage digestion in the rumen and predicting feed value. In: INTERNATIONAL GRASSLAND CONGRESS, 11., 1970, Surfers Paradise, 1970, St Lúcia. Proceedings... St Lúcia: University of Queensland Press, 1970. p.697-701.

COLUCCI, P.E. Comparative digestion and digesta kinetics in sheep and cattle. 1984. 166p. Thesis - University of Guelph, 1984.

EUCLIDES, V.P.B., THIAGO, L.R.L.S., OLIVEIRA, M.P. Consumo de forragem por novilhos pastejando cinco gramíneas. In: REUNIAO ANUAL DA SOCIEDADE BRASILEIRA DE ZOOTECNIA, 30., 1993, Rio de Janeiro, RJ. Anais... Rio de Janeiro: SBZ, 1993. p.491.

EUCLIDES, V.P.B., THIAGO, L.R.L.S., MACEDO, M.C.M. et al. 1999. Consumo voluntário de forragem de três cultivares de Panicum maximum sob pastejo. R. Soc. Bras. Zootec., 28(6):1177-1185.

FURLAN, C.L.F. Estimativas da disponibilidade da forragem, composição da extrusa e consumo de matéria seca de vacas em lactação sob pastejo intensivo de capim "coastcross" (Cynodon dactylon (L.) Pers). Jaboticabal, SP: UNESP, 1998. 75p. Dissertação (Mestrado em Zootecnia) Faculdade de Ciências Agrárias e Veterinárias, Universidade Estadual Paulista, 1998.

HOVELL, F.D.B., NGAMBI, J.W.W., BARBER, W.P. et al. 1986. The voluntary intake of hay by sheep in relation to its degradability in the rumen as measured in nylon bags. Anim. Prod., 42(1):111-118.

MAcDOUGALL, E.I. 1939. Studies on ruminant saliva. I. The composition and output of sheep's saliva. Biochemical J., 43(1):99-109.

McDONALD, I. 1981. A revised model for the estimation of protein degradability in the rumen. J. Agric. Sci., 96(1):251-252.

MADSEN, J., HVELPLUND, T., WEISBJERG, M.R. 1997. Appropriate methods for evaluation of tropical feeds for ruminants. Anim. Feed Sci. Tech., 69(2):53-66.

MADSEN, J., STENSING, T., WEISBJERG, M. R. et al. 1994. Estimation of the physical fill of feedstuffs in the rumen by the sacco degradation characteristics. Livest. Prod. Sci., 39(1):43-47.

MEHREZ, A.Z., ØRSKOV, E.R. 1977. A study of the artificial fiber bag technique for determing the digestibility of feeds in the rumen. J. Agric. Sci., 88(3):645-665.

MERTENS, D.R. Regulation of forage intake.1994. In: FAHEY JR., D.C. (Ed.) Forage quality, evaluation and utilization. Madson: American Society of Agronomy. p.450-492.
MERTENS, D.R. 1987. Predicting intake and digestibility using mathematical models of ruminal function. J. Anim. Sci., 64(8):1548-1558

NOCEK, J.E. , KOHN, R.A. 1988. In situ particle size reduction of alfafa and timothy hay as influence by form and particle size. J. Dairy Sci., 71(4):932-945.

ØRSKOV, E.R., REID, G.W., KAY, M. 1988. Predicting of intake by cattle from degradation characteristics of roughages. Anim. Prod., 46(1):29-34.

ØRSKOV, E.R., MCDONALD, I. 1979. The estimation of protein degradability in the rumen from incubation measurements weighed according to rate of passage. J. Agric. Sci., 92 (1):499-503.

OWENS, F.N., HANSON, C.F. 1992. External and internal markers for appraising site and extent of digestion in ruminants. J. Dairy Sci., 75(9):2605-2617.

PIAGGIO, L.M., PRATES, E.R., PIRES, F.F. et al. 1991. Avaliação do cromo mordente como indicador externo da produção fecal. R. Soc. Bras. Zootec., 20(3):313-318.

POND, K.R., ELLIS, W.C., MATIS, J.H. et al. 1989. Passage of chromium-mordanted and rare earth-labeled fiber: time of dosing kinetics. J. Anim. Sci., 67(4):1020-28.

SALMAN, A.K.D. Degradabilidade in situ e consumo voluntário do capim Tanzânia (Pannicum maximum, J.c.v. Tanzânia), sob pastejo, por vacas em lactação. Jaboticabal, SP: UNESP, 1999. 62p. Dissertação (Mestrado em Zootecnia) - Faculdade de Ciências Agrárias e Veterinárias, Universidade Estadual Paulista, 1999.

SAS INSTITUTE. 1990. SAS user's guide: statistics. Cary, N.C 956p.

SHEM, M.N., ØRSKOV, E.R., KIMAMBO, A.E. 1995. Prediction of voluntary dry-matter intake, digestible drymatter intake and growth rate of cattle from degradation characteristics. J. Anim. Sci., 60(1):65-74.

TILLEY, J.M.A., TERRY, R.A. 1963. A two stages techinique for the "in vitro" digestion of forage crops. J. Br. Grassl. Soc., 18(2):104-111.

VAN SOEST, P.J. 1994. Nutritional ecology of the ruminant. 2.ed. Ithaca: Cornell University, Ithaca. 476p.

VAN SOEST, P.J. 1965. Symposium on factors influencing the voluntary intake of herbage by ruminants: voluntary intake relation to chemical composition and digestibility. J. Anim. Sci., 24(3):834-844.

VON KEYSERLINGK, M,A.G., MATHISON, G.W. 1989. Use of the in situ technique and passage rate constants in predicting voluntary intake and apparent digestibility of forrages by steers. Can. J. Anim. Sci., 69(5):973-987.

Recebido em: 26/10/00 Aceito em: 03/07/01 